\title{
Leptin-induced transphosphorylation of vascular endothelial growth factor receptor increases Notch and stimulates endothelial cell angiogenic transformation.
}

Viola Lanier ${ }^{\text {a }}$, Corey Gillespie ${ }^{\text {b }}$, Merle Leffers ${ }^{\text {c }}$, Danielle Daley-Brown ${ }^{\text {a }}$, Joy Milner ${ }^{\text {a }}$, Crystal Lipsey a, Nia Webb a, Leonard M. Anderson ${ }^{\mathrm{a}, \mathrm{d}}$, Gale Newman ${ }^{\text {a, }}$ Johannes Waltenberger ${ }^{\mathrm{c}}$, Ruben Rene Gonzalez-Perez ${ }^{\mathrm{a}}$

${ }^{a}$ Department of Microbiology, Biochemistry and Immunology, Morehouse School of Medicine, Atlanta, GA 30310.

${ }^{\mathrm{b}}$ Atlanta Technical College, Bioscience Technology Program, Atlanta, GA 30310.

${ }^{\mathrm{c}}$ Universitätsklinikum Münster, Munster, Germany.

${ }^{\mathrm{d}}$ Cardiovascular Research Institute, Morehouse School of Medicine, Atlanta, GA 30310.

Corresponding author: Ruben Rene Gonzalez-Perez

Department of Microbiology, Biochemistry and Immunology, Morehouse School of Medicine, 720 Westview Dr. SW., Hugh Gloster Bldg., Suite 329, Atlanta, GA 30310.

T: 404-752-1581

F: 404-752-1179

Email: rgonzalez@msm.edu 


\begin{abstract}
Leptin increases vascular endothelial growth factor (VEGF), VEGF receptor-2 (VEGFR-2), and Notch expression in cancer cells, and transphosphorylates VEGFR-2 in endothelial cells. However, the mechanisms involved in leptin's actions in endothelial cells are not completely known. Here we investigated whether a leptin-VEGFR-Notch axis is involved in these leptin's actions. To this end, human umbilical vein and porcine aortic endothelial cells (wild type and genetically modified to overexpress VEGFR-1 or -2) were cultured in the absence of VEGF and treated with leptin and inhibitors of Notch (gamma-secretase inhibitors: DAPT and S2188, and silencing RNA), VEGFR (kinase inhibitor: SU5416, and silencing RNA) and leptin receptor, OB-R (pegylated leptin peptide receptor antagonist 2: PEG-LPrA2). Interestingly, in the absence of VEGF, leptin induced the expression of several components of Notch signaling pathway in endothelial cells. Inhibition of VEGFR and Notch signaling significantly decreased leptin-induced S-phase progression, proliferation, and tube formation in endothelial cells. Moreover, leptin/OB-R induced transphosphorylation of VEGFR-1 and VEGFR-2 was essential for leptin's effects. These results unveil for the first time a novel mechanism by which leptin could induce angiogenic features via upregulation/trans-activation of VEGFR and downstream expression/activation of Notch in endothelial cells. Thus, high levels of leptin found in overweight and obese patients might lead to increased angiogenesis by activating VEGFR-Notch signaling crosstalk in endothelial cells. These observations might be highly relevant for obese patients with cancer, where leptin/VEGFR/Notch crosstalk could play an important role in cancer growth, and could be a new target for the control of tumor angiogenesis.
\end{abstract}

Keywords: leptin, VEGFR, Notch, endothelial cells, angiogenesis, tumor angiogenesis 


\section{Introduction}

Endothelial cells (EC) play a major role in normal biological processes such as blood-tissue exchange, blood-cell activation, vasculogenesis, and angiogenesis. EC line the blood vasculature, regulate vascular homeostasis, and form a barrier to create the endothelium; which acts as a vessel for the circulating blood. Under the actions of several circulating factors EC can modify the phenotype of the vessel wall (Aird, 2007). Vascular endothelial growth factor (VEGF) and its receptor type 2 (VEGFR-2) play major roles in these processes (Hoeben et al., 2004). VEGFR-2 is a kinase insert domain receptor encoded by the human KDR gene, which corresponds to the FLK-1 mouse gene. It plays an essential role in the angiogenic process in physiologic and pathological scenarios (Fischer et al., 2006). VEGFR-2 is a major mitogenic and chemotactic receptor expressed by EC and other cells, which can induce several cellular processes common to many growth factor receptors, such as, cell proliferation, migration, survival, and vascular development (Ferrara et al., 2003; Garonna et al., 2011). In addition, VEGF/VEGFR-2 autocrine/paracrine signaling is essential for survival of breast cancer cells (Guo et al., 2010).

Notch is also an important factor involved in angiogenesis. When activated, Notch intracellular domain (NICD) induces proliferation, differentiation, and survival of EC that in turn increases angiogenesis. Abnormal expression/activation of Notch correlates to cancer development and poor outcomes (Guo et al., 2011). The Notch receptor family is composed of four members, Notch1, Notch2, Notch3, and Notch4. Notch1 is considered a hallmark of breast cancer, and is generally overexpressed in tumor tissues. In contrast, Notch receptors are modestly expressed in normal breast tissue (Guo et al., 2011). Several ligands of Notch: Jagged1, Jagged2, and Delta-like ligands (DLL1, DLL3, and DLL4) are also abnormally expressed in cancer tissues. Notch1 and DLL4 have been shown to be expressed in human umbilical vein endothelial cells (HUVEC) and upregulated by VEGF/VEGFR signaling (Liu et al., 
2003). Ligand binding to Notch receptors on adjacent cells leads to the activation of signaling pathways. The protease, gamma-secretase, is an essential enzyme involved in NICD formation. A series of proteolysis events involving gamma-secretase, cleave and activate Notch receptors leading to the formation of NICD; which binds CSL/RBP-Jk, a transcription factor in the nucleus and leads to activation of several genes (e.g., survivin and Hey2).

The molecular signature of tip EC forming capillaries is characterized by the expression of VEGFR-2, DLL4, and other receptors (Gerhardt et al., 2003). Notch and VEGF/VEGFR-2 signaling pathways have been shown to promote a switch from stalk to tip EC; thus promoting differentiation and migration of tip EC that become highly polarized and extend their filopodia to form capillaries (Gerhardt et al., 2003). Notch signaling in stalk EC impairs filopodia extension, promotes tube length by cell proliferation, and inhibits vessel branching by lowering expression of VEGFR-2 and other receptors (Tammela et al., 2008; Williams et al., 2006). Notch induces lateral inhibition of EC during tip-stalk cell fate switching, which involves DLL4/Notch signaling (Hellstrom et al., 2007a; Noguera-Troise et al., 2006; Suchting et al., 2007).

Leptin is a small $(16 \mathrm{kD})$ and non-glycosylated cytokine secreted by adipocytes and cancer cells that promotes angiogenesis in physiological and pathological contexts (Halaas et al., 1995; SierraHonigmann et al., 1998). The leptin receptor, OB-R, is mainly expressed in hypothalamic cells, but also in peripheral cells including EC (Guo et al., 2012; Schroeter et al., 2007). Obese individuals exhibit the highest levels of leptin and usually develop leptin-resistance; where leptin cannot control appetite or energy balance (Halaas et al., 1995; Sierra-Honigmann et al., 1998). Increased leptin signaling correlates to an enhanced expression of proteins, and is involved in cancer progression and tumor angiogenesis (Gonzalez-Perez et al., 2013). Leptin signaling has been shown to regulate VEGF/VEGFR-2 and Notch and its targets in breast cancer (Guo and Gonzalez-Perez, 2011). Additionally, a crosstalk between Notch, leptin, and IL-1 signaling (NILCO) affects the expression of pro-angiogenic molecules, leading to cell proliferation and migration of breast cancer cells (Guo and Gonzalez-Perez, 2011). Therefore, leptin 
secreted by adipocytes and cancer cells could be an important factor contributing to tumor angiogenesis by acting directly on EC. In addition, leptin can increase tumor angiogenesis by inducing VEGF secretion (Garonna et al., 2011). However, the mechanisms involved in leptin's actions on EC are not completely understood. Thus, the aim of this investigation is to determine whether leptin could induce the angiogenic transformation in EC via activation of VEGFR and Notch independently of VEGF.

\section{Materials and Methods}

\subsection{Reagents and antibodies}

Human recombinant leptin, human VEGFR-2 Quantikine ELISA Kits, and human VEGF cytokine (293-VE) was purchased from R\&D Systems, Minneapolis, MN. Notch1 (sc-373891), Notch4 (sc-56594) and Jagged1 (JAG1, sc-8303) polyclonal antibodies were obtained from Santa Cruz Biotechnology, Santa Cruz, CA. DLL4 (ab7280), Notch2 (ab8926), and Notch3 (ab23426) polyclonal antibodies were purchased from Abcam, Cambridge, MA. VEGFR-2 monoclonal antibody (55B11) was purchased from Cell Signaling, Danvers, MA. Anti-mouse and anti-rabbit polyclonal antibodies conjugated to horseradish peroxidase were from Bio-Rad Laboratories, Hercules, CA. SU5416 was purchased from Sellekchem, Houston TX. Enhanced chemiluminescence (ECL)-western blot stripping buffer was from Thermo Scientific, Rockford, IL. Pegylated leptin receptor antagonist 2 (PEG-LPrA2) was prepared by us as previously described (Gonzalez and Leavis, 2003). Beta-actin (A5316) and GAPDH (glycerol aldehyde phosphate dehydrogenase; G8795) monoclonal antibodies, protease and phosphatase inhibitor cocktails 1 and 2, fetal bovine serum (FBS), DAPT [ $\mathrm{N}$-[N-(3,5-difluorophenacetyl)L-alanyl]-S-phenylglycine t-butyl ester], 4',6-diamidino-2-phenylindole] and S2188 gamma-secretase inhibitors, and other chemicals were purchased from Sigma-Aldrich, St. Louis, MO. 


\subsection{Endothelial Cell Cultures}

HUVEC (Invitrogen, Grand Island, NY) were cultured in Medium 200 (Invitrogen) containing $10 \%$ fetal bovine serum (FBS, Med Supply Partners, Inc.) plus P/S [1\% penicillin/streptomycin (Gibco, Inc.], $20 \mu \mathrm{g} / \mathrm{ml}$ of EC growth supplement (Millipore Inc.), and $0.4 \mu \mathrm{g} / \mathrm{ml} \mathrm{Geneticin} \mathrm{(Life} \mathrm{Technologies).}$ Wild type porcine aortic EC (PAEC, that do not express VEGFR-1 or VEGFR-2) and PAEC transfected with VEGFR-1 or VEGFR-2 cultured in Hams F-12 Medium (Invitrogen) containing 10\% FBS and P/S, were used as negative and positive control models, respectively, to determine the impact of leptin and the mechanism associated with VEGFR signaling (Waltenberger et al., 1994). EC cultures were carried out at $37^{\circ} \mathrm{C}$ in $5 \% \mathrm{CO} 2 / 95 \%$ air in $25 \mathrm{~mm}^{2}$ tissue culture flasks with cells in maximum passage equal to five.

\subsection{Leptin induction of Notch}

Semi confluent EC were further cultured in FBS deprived medium for 24 hours. Then, EC were cultured in medium containing human recombinant leptin $(0.6,1.2$, and $6.2 \mathrm{nM}$, which are equivalent to blood levels of leptin in lean and obese individuals) and inhibitors of OB-R (pegylated LPrA-2; 1.2-6.2 $\mathrm{nM}$ ), Notch (gamma-secretase inhibitors: DAPT $5 \mu \mathrm{M}$ and S2188 $10 \mathrm{nM}$ in 0.1\% DMSO), and VEGFR-2 (Semaxinib/SU5416; $5 \mu \mathrm{M}$ ). Notch expression in cell lysates was investigated using western blot (WB) and real time polymerase chain reaction (RT- PCR).

\subsection{Leptin induction of cell proliferation}

HUVEC were cultured in serum-supplemented medium at a density of 10,000 cells/well in 96well culture plates for 24 hours; and then cultured in FBS-deprived medium for an additional 16 hours. Cells were treated with leptin and inhibitors as described above. Cell proliferation was determined using MTT (3-(4,5-dimethylthiazol-2-yl)-2,5-diphenyl tetrazolium bromide) assay. Optical density (OD) values 
corresponding to formazan formation were recorded at $540 \mathrm{~nm}$ on a Microplate Reader (Spectramax). The results were expressed relative to the OD value of untreated HUVEC.

\subsection{Leptin induction of cell cycle progression}

HUVEC were plated in 12-well cell culture plates at a density of 100,000 cells/well in culture medium for 24 hours; and then in FBS deprived-medium for an additional 24 hours. Cells were treated as described above. Propidium iodide staining was used to quantify DNA content and cell cycle progression was measured using a Cellometer device (Nexcelom; Lawrence, MA). Gated cells were counted and expressed as percentage of untreated HUVEC.

\subsection{Western blot analysis}

Total proteins were extracted from EC on ice using radioimmunoprecipitation assay (RIPA) buffer and a protease/phosphatase inhibitor cocktail (Sigma). Protein concentrations of tissue lysates were determined using the Bradford method (Bio-Rad). Fifty micrograms of protein lysates were used for WB analysis as previously described (Gonzalez-Perez et al., 2010). After electrophoresis, protein bands were transferred onto nitrocellulose membranes (BioRad), which were incubated with specific primary antibodies for Notch1, Notch2, Notch3, Notch4, Jagged1, DLL4, and non-phosphorylated and phosphorylated (p)VEGFR-2 at $4^{\circ} \mathrm{C}$ overnight. Beta-Actin or GAPDH were used as loading controls. Image $\mathbf{J}$ software program (The National Institute of Health, NIH) was used for protein quantitative analysis.

2.7 VEGF and VEGFR-2 determinations 
VEGF levels in culture supernatants were determined by enzyme-linked immunoassay (VEGFELISA, R\&D system; sensitivity: $15 \mathrm{pg} / \mathrm{ml}$ ). Recombinant VEGF was used as a positive control. Additionally, pVEGFR-2 levels were determined in EC lysates (VEGFR-2 ELISA, R\&D System; sensitivity: $5 \mathrm{pg} / \mathrm{mL}$ ). All determinations and calibrations were carried out in triplicate.

\subsection{Real-time PCR}

To determine mRNA Notch expression, total RNA from EC was extracted and purified using RNeasy Mini Kit (Qiagen) following the manufacturer's protocol. Complementary deoxyribonucleic acid (cDNA) was synthesized from total RNA using SuperScript First-Strand Synthesis System with SuperScript II reverse transcriptase according to the manufacturer's protocols (Bio-Rad). cDNA was used as a template for RT-PCR with SYBR-Green PCR master-mix, and iQ5 RT-PCR detection System. RT-PCR reactions consisted of 1x SybrGreen Supermix, $0.20 \mathrm{nmol} / \mathrm{L}$ forward and reverse primers, and $1 \mu \mathrm{g}$ of cDNA. To generate a standard curve, amplified cDNA from the reference sample was obtained using a five-fold dilution series of cDNA per reaction. Relative gene expression was calculated by dividing the specific expression value by the corresponding expression of GAPDH. Primers include Notch1 forward primer: 5'-GTCAACGCCGTAGATGACC-3', reverse primer: 5'TTGTTAGCCCCGTTCTTCAG-3', Notch2 forward primer: 5'-TCCACTTCATACTCACAGTTGA-3', reverse primer: 5'-TGGTTCAGAGAA AACATACA-3', Notch3 forward primer: 5'-GGGAA AAAGGCAATAGGC-3', reverse primer: 5'-GGAGGGAGAAGCCAAGTC-3', Notch4 forward primer: 5'-AACTCCTCCCCAGGAATCTG-3', reverse primer: 5'-CCTCCATCCAGCAGAGGTT-3', DLL4 forward primer: 5'-TCCAACTGCCCTTCAATTTCAC-3', $\quad$ reverse primer: 5'CTGGATGGCGATCTTGCTGA-3'， Jagged-1 forward primer: 5'-GGAGGCGTGGGATTCCA-3'; reverse primer: 5'-CCGAGTGAGAAGCCTTTCAATAAT-3' and GAPDH, forward primer: 5'ATGGGGAAGGTGAAGGTCG-3' and reverse primer: 5'-GGGGTCATTGATGGCAACAATA-3' 
(Qiagen). PCR conditions consisted of: 1 cycle, $95^{\circ} \mathrm{C}$ for $3 \min (45 \mathrm{cycles}), 95^{\circ} \mathrm{C}$ for $30 \mathrm{sec} ; 52^{\circ} \mathrm{C}$ for 30 sec and $72^{\circ} \mathrm{C}$ for $30 \mathrm{sec}$. Annealing temperatures varied around $61^{\circ} \mathrm{C}$. RT-PCR determinations were performed in triplicate.

\subsection{Small interfering $R N A$}

Knock down of VEGFR-1/FLT-1, VEGFR-2/FLK-1, Notch1, Notch3, and CSL/RBP-Jk gene expression in EC was achieved using specific small interfering RNA (SiRNA, Qiagen). EC were seeded at a density of $2 \times 10^{5} / \mathrm{ml}$ and cultured until $60 \%$ confluence in growth medium without antibiotics in 12 well plates. Cells were then transfected with VEGFR-1, VEGFR-2, Notch1, Notch3, or CSL/RBP-Jk oligonucleotides (an essential transcription factor for Notch signaling; $10 \mathrm{nM}$ ) that were composed of three to five specific siRNA targets of 19-25 nucleotide length (Qiagen). Negative controls included scramble SiRNAs (SiControl). EC were incubated at $37^{\circ} \mathrm{C}$ for 6 hours in serum-free transfection medium (Qiagen). After SiRNA transfection, EC were cultured at $37^{\circ} \mathrm{C}$ for an additional 24 hours in normal growth medium with antibiotics, $10 \%$ FBS, and transfection medium. Cell lysates were analyzed by WB for VEGFR-1, VEGFR-2, Notch1, Notch3, and CSL protein expression.

\subsection{Matrigel assay (tube formation)}

EC were cultured in M200 medium containing 5\% FBS and $5 \mathrm{mg} / \mathrm{ml}$ of EC growth factor (ECGF, Millipore). The effects of leptin and inhibitors of VEGFRs and Notch on EC ability to form tube-like structures in vitro were determined by Matrigel Matrix assays (BD Sciences). VEGF was used as positive a control. Growth factor-reduced Matrigel was plated onto 96-well plates (200 $\mu 1 /$ well) and incubated at $37^{\circ} \mathrm{C}$ for 30 minutes. HUVEC were seeded in the Matrigel-coated plates at 10,000 cells/well, and treated with leptin $(1.2 \mathrm{nM})$, SU5416 $(5 \mu \mathrm{mol} / \mathrm{L})$, and DAPT $(5 \mu \mathrm{mol} / \mathrm{L})$ in $1 \%$ reduced FBS medium. After 8 hours, the cells were washed twice in PBS and fixed in 4\% paraformaldehyde. Images of tube formation were captured at 10X using an inverted microscope. Quantitative determination of HUVEC tube 
formation was carried out using Image Pro Plus software. The visible tubes were counted using the software, and the analyses of vessel average length and area $\left(\mathrm{mm}^{2}\right)$ were performed.

\subsection{Statistical Analysis}

Statistical analysis was performed using one-way ANOVA and student t-test to compare results between treatment groups. All experiments were repeated 3 or more times. Data is presented as an average \pm standard deviation. $\mathrm{P}<0.05$ was considered to be statistically significant.

\section{Results}

3.1 VEGFR-2 and Notch activities are essential for leptin-induced angiogenic features in endothelial cells

The ability of leptin to induce EC-derived tube-like structures in the absence of VEGF was assessed. DAPT (an inhibitor of gamma secretase that activates Notch) and SU5416 inhibitors were used to determine whether activity of Notch and VEGFR-2, respectively, are required for leptin-induction of HUVEC proliferation. Leptin was shown to increase tube-like structure formation in HUVEC (Fig. 1A and B). The addition of DAPT to HUVEC cultures treated with leptin significantly decreased tube-like structure formation (Fig. 1A and B). Moreover, the inhibition of VEGFR-2 signaling via SU5416 (a selective tyrosine kinase inhibitor of VEGFR-2) also reduced leptin-induced tube-like formation (Fig. 1A and B). Leptin induced EC proliferation in the absence of VEGF as was shown from MTT cell proliferation assay data (Fig. 1C). However, leptin failed to promote HUVEC proliferation when Notch or VEGFR-2 was inhibited via DAPT and SU5416, respectively (Fig. 1C). Furthermore, data from HUVEC treated with leptin and an additional gamma-secretase inhibitor, S2188, assessed that inhibition of Notch activation negatively impaired leptin-induced EC proliferation (Fig. 1D). Moreover, inhibition of 
VEGFR-2 and Notch blocked leptin-induced S-phase progression in HUVEC as determined by Cellometer (Fig. 1E). These results suggest that leptin's pro-angiogenic effects on EC involve Notch and VEGFR-2 signaling.

To test specificity of leptin effects on HUVEC, PEG-LPrA-2 was used. Addition of PEG-LPrA-2 blocked leptin-induced tube formation, proliferation, and S-phase progression in HUVEC (Fig. 1A, B and E). The addition of VEGF to HUVEC induced proliferation and S-phase progression to a similar degree than leptin (Fig. 1C and E). However, VEGF (25 ng/ml equivalent to $1.3 \mathrm{nM}$ ) showed superior ability than leptin $(1.2 \mathrm{nM})$ to induce tube formation in HUVEC (Fig. 1A and B).

\subsection{Leptin induces expression of Notch protein and $\mathrm{mRNA}$}

To determine whether leptin affects Notch expression and its targeted molecules in EC, WB and RT-PCR were performed. $1.2 \mathrm{nM}$ of leptin (in the absence of VEGF) induced Notch in EC (Fig. 2A). HUVEC treated with the lower dose of leptin assayed $(0.6 \mathrm{nM})$ showed increased protein expression of Notch1, Notch2, and DLL4 (Fig. 2A and B). Leptin (1.2 nM) induced all Notch receptors and ligands assayed and mRNA expression (Fig. 2B). Higher leptin concentration (6.2 nM) increased several proteins and Notch2, DLL4, and Jagged1 mRNA in HUVEC (see Fig. 2B).

Time response experiments showed that leptin $1.2 \mathrm{nM}$ increased the levels of Notch2 and Notch4 proteins in HUVEC after 12 hours. Moreover, HUVEC increased all Notch molecules (Fig. 3C and D) investigated after incubation with leptin for 24 and 48 hours (Fig. 3B).

To investigate whether leptin-induced VEGFR transactivation regulates Notch, wild type PAEC (that lack VEGFR-1 or VEGFR-2 expression) (Kroll and Waltenberger, 1997) and VEGFR-transfected PAEC (that overexpress VEGFR-1 or VEGFR-2) were challenged with leptin (0-6.2 nM). Firstly, PAEC (wild type and VEGFR-transfected) were analyzed by WB for expression of VEGFR-1 and VEGFR-2. As 
expected, wild-type PAEC did not express detectable levels of VEGFR-1 or VEGFR-2 proteins (Fig. 4A). In contrast, VEGFR- transfected PAEC express VEGFR-1 or VEGFR-2 (Fig. 4A). It was also determined that the PAEC used express leptin receptor, OB-R (Fig. 4B). Wild type PAEC (lacking VEGFR-1 and VEGFR-2) cultured in basal conditions or cultured with leptin did not express detectable quantities of Notch proteins (data not shown). In contrast, PAEC VEGFR-1 and VEGFR-2 expressed some Notch proteins in basal conditions (Fig. 4C and 4D). PAEC VEGFR-1 challenged with leptin showed increased levels of Notch3, Notch4, and Jagged1 proteins (Fig. 4C). Similar results were found in PAEC VEGFR-2 cells treated with leptin, but Notch1 protein was also upregulated (Fig. 4D). In comparison, leptin induced higher levels of Notch proteins in PAEC overexpressing VEGFR-2 (see Fig. 4C and D). Additionally, HUVEC (that express VEGFR-1 and VEGFR-2) treated with leptin showed increased protein levels of Notch receptors and ligands (see Fig. 1A).

Additionally, leptin induced Notch3 mRNA in PAEC VEGFR-1 (Fig. 5B), and Notch3, Notch4, and DLL4 mRNA in PAEC VEGFR-2 (Fig. 5C). Moreover, HUVEC treated with leptin showed increased mRNA levels of all Notch molecules investigated (see Fig. 2B). This data further suggest that leptin induces Notch in EC, and VEGFR activity is likely involved in these effects of leptin.

\subsection{Leptin induction of Notch in EC involves VEGFR activity}

To further explore the mechanisms underlying the role of VEGFR in leptin induction on Notch expression in EC, SU5416 was added to HUVEC cultures that were also treated with $1.2 \mathrm{nM}$ of leptin. Additionally, VEGF was used as a positive control. Inhibition of VEGFR-2 kinase activity via SU5416 blocked leptin-induced expression of Notch1, Notch2, Notch3 and Notch4 proteins in HUVEC (Fig. 6A). These findings further suggest that leptin's induction of Notch in EC involves VEGFR kinase activity.

To additionally investigate the role of VEGFR in leptin-induced Notch expression, knockdown of VEGFR-2 was carried out via siRNA. Remarkably, VEGFR-2 SiRNA transfection blocked leptin- 
induced expression of Notch2, Notch3, Notch4, and Jagged1 proteins in HUVEC (Fig. 6B). However, silencing VEGFR-2 did not alter the levels of leptin-induced Notch1 and DLL4 proteins (see Fig. 6B). Additionally, double silencing of VEGFR-1 and VEGFR-2 was carried out in HUVEC treated with leptin. Double knockdown of VEGFR-1 and VEGFR-2 inhibited leptin-induced expression of Notch2, Notch3, and Notch4 proteins (Fig. 6C). However, Notch1 protein was upregulated in HUVEC after knockdown of VEGFR-1 and VEGFR-2, which might suggest other mechanisms are involved in leptin's induction of Notch1 in HUVEC.

In order to further investigate the role of VEGFR in leptin-induced effects, Notch mRNA levels were determined in HUVEC treated with leptin and transfected with VEGFR-2 SiRNA or double VEGFR-1 and VEGFR-2 SiRNA. mRNA silencing of VEGFR-1 and VEGFR-2 effectively decreased mRNA levels of these receptors (Fig. 6D). Notch1, Notch3, and Notch4 mRNA levels were significantly decreased in HUVEC transfected with VEGFR-1 and VEGFR-2 siRNA and treated with leptin (Fig. 6D). Additionally, the knockdown of VEGFR-2 significantly reduced Notch2 mRNA in HUVEC treated with leptin. However, Notch1 mRNA was increased by VEGFR-2 siRNA transfection (Fig. 6D).

\subsection{Leptin-induced VEGFR-2 expression and phosphorylation in EC involves Notch signaling and VEGFR-2 kinase activity}

We further determined that HUVEC and PAEC cultured in basal conditions or medium containing leptin do not secrete detectable levels of VEGF (Fig. 7A) (Garonna et al., 2011; Waltenberger et al., 1996). However, leptin enhanced the expression of VEGFR-2 protein in HUVEC (Fig. 7B). Moreover, it was found that leptin upregulation of VEGFR-2 protein in HUVEC involves Notch activity, as DAPT inhibition of Notch-activating enzyme (gamma-secretase) reduced leptin's effects (Fig. 7C). To further investigate whether Notch signaling is involved in leptin-induced expression of VEGFR-2 in HUVEC, Notch1, Notch3, and CSL/RBP-Jk were knocked down via siRNA. HUVEC treated with leptin 
and transfected with Notch1, Notch3, and CSL/RBP-Jk SiRNA showed decreased levels of leptininduced VEGFR-2 protein (Fig. 7C) and mRNA (Fig. 7D). It was assessed that Notch silencing treatment significantly decreased the levels of Notch1 and Notch3 (see Fig. 7D).

It was further assessed that leptin/OB-R signaling transphosphorylates VEGFR-2 in HUVEC in the absence of VEGF (Fig. 7E and F) as was earlier reported (Garonna et al., 2011). Phosphorylated VEGFR-2 (pVEGFR-2) levels were increased in HUVEC treated with leptin, as determined by ELISA (Fig. 7E). These effects of leptin were diminished by inhibition of VEGFR-2 kinase activity (see Fig. 7E). To test if the effects of leptin were specific, HUVEC were treated with leptin and OB-R antagonist, PEG-LPrA-2, which decreased the levels of leptin-induced phosphorylated VEGFR-2 (see Fig. 7E). Moreover, WB analysis showed that leptin significantly increased transphosphorylation of several tyrosine sites in the intra-cytoplasmic VEGFR-2 tail in HUVEC and PAEC transfected with VEGFR-2 (Fig. 7F). Leptin enhanced the levels of phosphorylated VEGFR-2 at residues, Y951, Y996, and Y1175 in HUVEC, and Y966, Y1059, and Y1175 in PAEC VEGFR-2 (see Fig. 7F). Incubation of HUVEC with VEGF (positive control) induced similar VEGFR-2 phosphorylation as with leptin, but also increased phosphorylation of Y1059 (Fig. 7F).

\section{Discussion}

Leptin is a known regulator of normal and pathological angiogenesis (Bouloumie et al., 1998; Gonzalez-Perez et al., 2013). However, the specific mechanisms involved in leptin's actions are not completely understood. We earlier described that leptin upregulates the expression of VEGF in breast cancer cells through mechanisms involving several canonical signaling pathways and specific transcription factors (e.g., HIF and SP1) (Gonzalez-Perez et al., 2010). Furthermore, we found that leptin/OB-R signaling was linked to increased levels of VEGF/VEGFR-2 in breast cancer (Battle et al. 2014; Rene et al., 2009). Moreover, we previously found that leptin upregulates Notch in breast cancer, 
and that a complex crosstalk between Notch, IL-1, and leptin (NILCO) regulates the expression of angiogenic molecules (VEGF/VEGFR) in breast cancer cells (Battle et al., 2014; Gillespie et al., 2012; Guo and Gonzalez-Perez, 2011).

Wheeler-Jones and collaborators have previously shown that leptin induces the phosphorylation of VEGFR-2 (Y1175) in HUVEC independently of VEGF signaling (Garonna et al., 2011). Moreover, leptin was found to induce the angiogenic transformation of EC via COX-2 (cyclooxygenase 2) and activation of specific kinases, which was linked to increased VEGFR-2 phosphorylation in the absence of VEGF (Garonna et al., 2011). The inhibition of VEGFR-2 tyrosine kinase activity in HUVEC reduced leptin-stimulated pro-angiogenic responses. In addition, the blockade of VEGFR-2 or COX-2 activities abolished leptin-driven neo-angiogenesis in a chick chorioallantoic membrane vascularization assay in vivo (Garonna et al., 2011).

In the present work, we expanded these investigations by showing that leptin-induced proliferation and pro-angiogenic features of EC are related to leptin-induced expression, transphosphorylation, and activation of VEGFR-2, which mediates the upregulation of Notch expression and signaling; in the absence of VEGF. These effects of leptin involved the VEGF-independent transactivation of VEGFR-1 and/or VEGFR-2.

Here for the first time we show that leptin pro-angiogenic actions in EC are dependent on a functional OB-R/VEGFR/Notch signaling axis (Fig. 8). Indeed, the inactivation of OB-R (via PEGLPrA2), VEGFR kinase activity (via SU5416) or interfering with gene expression by SiRNA, and the inhibition of Notch activity via gamma-secretase inhibitors (DAPT and S2188), and Notch and CSL/RBP-Jk SiRNA impaired leptin-induced HUVEC proliferation, S-phase progression, and tube-like structure formation.

It is known that Notch signaling plays critical roles in cell fate determination and angiogenesis (Shawber et al., 2003; Takeshita et al., 2007). Notch1 and Notch4 receptors, DLL1, DLL4, and Jagged1 
ligands are predominantly found in the endothelium. Positive or negative modulation of Notch results in vascular pathologies. The Notch pathway is tightly regulated in EC by VEGF signals, but not by basic fibroblast growth factor (bFGF). VEGF signaling induces Notch1 and DLL4 gene expression in EC. Moreover, the Notch pathway is involved in a feedback loop with VEGF (Hellstrom et al., 2007a).

The regulation of Notch/DLL gene expression by VEGF was found to be critical for arteriogenesis and angiogenesis. VEGF regulates fate and phenotypic changes of EC during the formation of capillaries and the formation of tip cells during angiogenesis via Notch1/DLL4 activity (Hellstrom et al., 2007b). Additionally, Notch1 induced signals have been implicated in other angiogenic functions (e.g., formation of hematopoietic stem cells from EC (Kumano et al., 2003). However, the signaling mechanisms controlling Notch receptor and ligand gene expression in EC are not completely known.

Previous findings show that VEGFR-1 and VEGFR-2 receptor signaling are necessary for tumor angiogenesis and EC migration and proliferation (Holmqvist et al., 2004; Lee et al., 2010; Matsumoto et al., 2005). Present data suggest that leptin is a novel inducer of Notch in EC via transactivation of VEGFR. Our results indicate that leptin regulates specific Notch receptors and ligands in EC either through transactivation of VEGFR-2 or the heterodimer pair (VEGFR-1 and VEGFR-2). Leptin upregulation of Notch was linked to both VEGFR-1 and -2 activities, as the simultaneous knock down of these receptors abolished the majority of leptin effects on Notch. Therefore, leptin's actions could involve VEGFR-1/VEGFR-2 heterodimer signaling. The simultaneous knockdown of VEGFR-1 and VEGFR-2 inhibited leptin-induced Notch1 mRNA but was unable to block leptin upregulation of Notch1 protein, which suggest additional mechanisms independent of VEGFR signaling could be involved in leptininduced Notch1 expression in EC. The specific biological relevance of these findings needs to be further investigated. Dissimilar transcription and translation rates could indicate that changes in gene expression level are not reflected at the protein level (Vogel and Marcotte, 2012). 
In this investigation we assessed that leptin induced the transphosphorylation of Y1175, Y951, and Y996 of VEGFR-2 in HUVEC in the absence of VEGF. Moreover, leptin's effects were more evident in PAEC-VEGFR-2 transfected cells. However, present data further show that leptin-induced trans-phosphorylation of VEGFR-2 is not equivalent to VEGF-induced VEGFR-2 phosphorylation, at least in terms of activated $\mathrm{Y}$ residues in the intracytoplasmatic tail of the receptor. We found that VEGF also induces the phosphorylation of Y1059 VEGFR-2 in HUVEC.

Of note, present results show that the blockade of Notch activation impaired leptin-induced EC angiogenic features, but also reduced leptin-induced VEGFR-2 phosphorylation. Taken together, the data supports the notion that leptin induction of Notch requires VEGFR-2 activity, which is in turn regulated by a Notch feedback in EC.

Remarkably, the actions of leptin on EC were independent of VEGF signaling. Therefore, leptin could re-enforce VEGF actions by stimulating Notch expression and activity, which can be linked to the progression of cell cycle, proliferation, and angiogenic differentiation of EC. However, the fact that VEGF and leptin actions induced different patterns of VEGFR-2 phosphorylation might suggest that additional undetermined mechanisms occur in EC, which may be linked to Notch expression, and leptininduced angiogenic features.

Present data suggest that leptin could have some redundant actions to VEGF on EC, which may profoundly affect angiogenesis; especially in obesity contexts, which are characterized by abnormally high levels of leptin. Previous research has shown that obesity and overweight conditions are strongly related to increased tumor angiogenesis (Battle et al., 2014; Gillespie et al., 2012), and the incidence and poor prognosis of several cancer types (Calle and Kaaks, 2004; Guo et al., 2012; Lipsey et al., 2016). Whether leptin induces Notch through VEGFR-2 activation during tumor angiogenesis has yet to be determined. 


\section{Conclusion}

Present data shows for the first time that leptin can induce Notch expression in EC through the VEGF-independent transactivation of VEGFR-1 and VEGFR-2. Moreover, leptin/OB-R signals induce a novel functional signaling axis in EC, leptin/VEGFR/Notch axis, which is essential for leptin-stimulated proliferation and angiogenic transformation of EC (see Fig. 8). Present findings further suggest that leptin/OB-R signaling could be a potential target for anti-angiogenesis therapies. Combination therapies targeting the leptin/VEGFR/Notch axis could be beneficial for cancer patients, particularly those showing high levels of leptin due to obesity or overweight conditions. However, present findings need to be further validated using in vivo models.

\section{Acknowledgments}

We thank deceased Professor Gary Sanford Ph.D. for his critical comments and scientific thinking that improved the quality of this manuscript. We also want to thank Gabriela Oprea-Ilies M.D. for her critical insights and edits, and Adriana Harbuzariu M.D., Tia Harmon MSc., and Courtney Dill MSc. for their help with Cellometer training and determinations. This work was supported by the National Cancer Institute at the National Institutes of Health (1R41 CA183399-01A1 to R.R.G.P.; 5U54 CA118638, S21 MD000101, 5G12 MD0076021, G12 RR026250-03, NIH RR03034 and 1C06 RR18386 to Morehouse School of Medicine), and the National Institute of General Medical Sciences, Research Initiative for Scientific Enhancement Program (RISE 5R25 GM058268 to L.V.) and the Congressionally Directed Medical Research Programs-Department of Defense (CDMRP DOD W81XWH-13-1-0382 to R.R.G.P).

This article does not contain any studies with human participants or animals performed by any of the authors. 


\section{Conflict of Interest}

The authors declare that they have no conflict of interest. 
Figure 1. VEGFR-2 and Notch activities are essential for leptin-induced cell proliferation, s-phase progression, and tube formation in endothelial cells

A. Leptin-induced tube-like formation in endothelial cells. Tube-like formation was analyzed in human umbilical vein endothelial cells (HUVEC) incubated in medium without (Basal) or containing leptin, VEGF, and inhibitors of VEGFR-2, leptin, and Notch. B. Quantitative determination of leptin-induced HUVEC tube-like formation. The graph shows tube-like formation calculated as vessel area $\left(\mathrm{mm}^{2}\right)$ using Image Pro Plus software. The visible tubes were counted using the software, and the analyses of vessel average length and area were performed. HUVEC were cultured for 24 hours in 96 well plates containing growth factor-reduced matrigel. Cells were treated with leptin (1.2 nM) and inhibitors of VEGFR-2 (SU5416; $5 \mu \mathrm{mol} / \mathrm{L}$ ), Notch (DAPT; $5 \mu \mathrm{mol} / \mathrm{L}$ ), and leptin receptor (LPrA2, $20 \mathrm{nM}$ ), and positive control VEGF $(25 \mathrm{ng} / \mathrm{ml})$. C. Leptin induces proliferation of endothelial cells. Results of MTT assay from HUVEC incubated as described in A. Absorbance was determined at $540 \mathrm{~nm}$, and data was evaluated with Spectramax software. D. Inhibition of gamma-secretase blocks leptin-induced HUVEC proliferation. HUVEC were incubated with leptin (0 and $1.2 \mathrm{nM})$ and S2188 (10 nM; Notch inhibitor), and proliferation was determined via MTT assay. E. Leptin induces S-phase progression in HUVEC. HUVEC were cultured as described in 12-well cell culture plates for 24 hours, and cell cycle progression was determined via Cellometer analysis (Nexelom). Quantitative analysis of propidium iodide-bound to DNA in S-phase gated cells was recorded. Data is presented as an average \pm s.d. from three independent experiments. a: $\mathrm{p}<0.05$ when compared to basal. $\mathrm{b}: \mathrm{p}<0.05$ when compared to endothelial cells treated with leptin. Su: SU5416. Magnification: 10X.

Figure2. Leptin dose-dependent induction of Notch protein and mRNA expression in endothelial cells

A. Leptin dose-dependent induction of Notch proteins. Western blot representative results of leptininduced Notch proteins in HUVEC. Cells were cultured in medium containing leptin $(0.6,1.2$, and 6.2 
nM) for 24 hours. Cell lysates were used to determine Notch protein expression after treatment. Betaactin was used as a loading control. Histograms show densitometric analysis of protein expression normalized to beta-actin as determined using NIH image $\mathbf{J}$ software. Relative protein expression was calculated as percentage to basal. B. Leptin induction of Notch mRNA. Quantitative results from RT-PCR of Notch mRNA expression in HUVEC exposed to leptin as described in A. RNA expression was calculated by normalizing values to GAPDH mRNA. Relative mRNA expression was calculated to basal. Data is presented as an average \pm s.d. from three independent experiments. $*$ p $<0.05$ when compared to basal.

\section{Figure 3. Leptin time-dependent upregulation of Notch proteins and mRNA in endothelial cells}

A. Leptin time-dependent induction of Notch proteins. Western blot representative results of leptin timedependent induction of Notch proteins in HUVEC. Cells were cultured in medium containing leptin (1.2 $\mathrm{nM}$ ) for 12,24 , and 48 hours. Notch protein expression was determined by WB. Beta-actin was used as a

loading control. Histograms show densitometric analysis of protein expression normalized to Beta-actin as determined using NIH image $\mathrm{J}$ software. B. Leptin time-dependent induction of Notch mRNA. Quantitative results from real-time PCR of Notch mRNA expression in HUVEC exposed to leptin as described in A. mRNA expression was calculated by normalizing values to GAPDH mRNA. Relative protein and mRNA expressions were calculated to basal. Data is presented as an average \pm s.d. from three independent experiments. ${ }^{*} \mathrm{p}<0.05$ when compared to basal.

\section{Figure 4. VEGF receptors are involved in leptin-induced Notch expression in endothelial cells}

A. VEGFR expression in PAEC. WB representative results of VEGFR in PAEC transfected with VEGFR1 and VEGFR-2. GAPDH was used as a loading control. B. Leptin receptor $(O B-R)$ expression in PAEC. WB representative results from OB-R immunoprecipitation (IP) in PAEC wild type, and PAEC transfected with VEGFR-1 and VEGFR-2. Cells lysates $\left(25 \mu \mathrm{g}\right.$ protein) were incubated at $4^{\circ} \mathrm{C}$ for 16 hours with anti-OB-R antibody $(0.5 \mu \mathrm{g})$. C. Leptin induction of Notch proteins in PAEC-VEGFR-1. Western blot (WB) representative results of leptin-induced Notch proteins in PAEC transfected with 
VEGFR-1. D. Leptin dose-dependent induction of Notch proteins in PAEC-VEGFR-2. PAEC transfected with VEGFR-1 and VEGFR-2 were cultured in medium containing leptin $(0.6,1.2$, and $6.2 \mathrm{nM})$ for 24 hours. Cell lysates were used to determine Notch protein expression after treatment. GAPDH was used as a loading control. Histograms show densitometric analysis of protein expression normalized to GAPDH as determined using NIH image $\mathbf{J}$ software. Relative protein expression was calculated as percentage to basal. WB analysis did not show basal or leptin-induced expression of Notch proteins in wild type PAEC. Protein G-agarose beads were added for IP/WB analysis. Data is presented as an average \pm s.d. from three independent experiments. $* \mathrm{p}<0.05$ when compared to basal.

\section{Figure 5. VEGF receptors are involved in leptin-induced Notch mRNA in endothelial cells}

A. Leptin dose-dependent induction of Notch mRNA in PAEC wild type; B PAEC-VEGFR-1 and $\boldsymbol{C}$. PAEC-VEGFR-2. Quantitative results from real-time PCR of Notch mRNA expression in PAEC wild type and PAEC transfected with VEGFR-1 and VEGFR-2. Cells were cultured in medium containing leptin $(0.6,1.2$, and $6.2 \mathrm{nM})$ for 24 hours. Cell lysates were used to determine Notch mRNA expression

after treatment. RNA expression was calculated by normalizing values to GAPDH mRNA. Relative mRNA expression was calculated to basal. Data is presented as an average \pm s.d. from three independent experiments. $* \mathrm{p}<0.05$ when compared to basal.

Figure 6. Inhibition of kinase activity and knockdown of VEGF receptors decrease leptin induction of Notch expression in endothelial cells

A. Leptin induction of Notch receptors in HUVEC requires VEGFR2 kinase activity. Western blot representative results from the reduction of leptin-induced Notch receptors via VEGFR kinase inhibition. HUVEC were treated for 24 hours with leptin (1.2 nM), VEGFR-2 inhibitor SU5416 (5 $\mu \mathrm{mol} / \mathrm{L})$ and positive control VEGF (25 ng/mL). B. Leptin induction of Notch proteins in HUVEC requires VEGFR-2 gene activity. Represented here are western blot results from the reduction of leptin-induced Notch via VEGFR-2 SiRNA knockdown. Results show the effects of VEGFR-2 SiRNA $(1 \mu \mathrm{g})$ after 6 hours on 
leptin-induced expression of Notch receptors and ligands in HUVEC. C. Leptin induction of Notch proteins in HUVEC is reduced by knockdown of VEGFR-1 and VEGFR-2 gene activities. Western blot representative results from the reduction of leptin-induced Notch via VEGFR-1 and VEGFR-2 SiRNA knockdown. D. Leptin induction of Notch mRNA in HUVEC is reduced by knockdown of VEGFR-1 and VEGFR-2 gene activities. Quantitative results from real-time PCR of Notch, VEGFR-1 and VEGFR-2 mRNA expression in HUVEC treated with leptin and VEGFR-1 and VEGFR-2 SiRNA. Beta-actin or GAPDH were used as loading controls. Relative protein expression was calculated as percentage to basal. Histograms show densitometric analysis of Notch protein expression using NIH image J software. RNA expression was calculated by normalizing values to GAPDH mRNA. Relative mRNA expression was calculated to basal. Data is presented as an average \pm s.d. from three independent experiments. Su: SU5416; SiControl: siRNA control. a: $p<0.05$ when compared to basal. $b: p<0.05$ when compared to endothelial cells treated with leptin.

Figure 7. Leptin-induced expression and phosphorylation of VEGFR-2 in endothelial cells is independent of VEGF

A. VEGF levels in culture supernatant from endothelial cells treated with leptin. HUVEC and PAEC VEGFR-2 cells were cultured for 24 hours with leptin $(0,0.6,1.2$, and $6.2 \mathrm{nM})$. VEGF165 levels $(\mu \mathrm{g} / \mathrm{ml})$ in cell culture supernatants were determined via ELISA (R\&D System). ELISA kit control (Ctr) and VEGF (positive control) were also tested. Assay dynamic range and sensitivity were $15.6-1,000 \mathrm{pg} / \mathrm{mL}$ and $5 \mathrm{pg} / \mathrm{ml}$, respectively. B. Leptin induction of VEGFR-2 protein in HUVEC is reduced by Notch inhibition. Represented here are western blot results from the effects of Notch inhibition on leptin induction of VEGFR-2. HUVEC were treated for 24 hours with leptin [0 (basal) and $1.2 \mathrm{nM}$ ], Notch inhibitor (DAPT, gamma-secretase inhibitor; $5 \mu \mathrm{mol} / \mathrm{L})$. VEGF $(25 \mathrm{ng} / \mathrm{ml})$ and VEGF+DAPT. GAPDH was used as a loading control. C. Leptin induction of VEGFR-2 protein in HUVEC is reduced by Notch knockdown. WB representative results of VEGFR-2 from the effects of mRNA silencing of Notch and 
CSL. HUVEC wild type and transfected with Notch1, Notch3, and CSL SiRNA were treated for 24 hours with leptin [0 (basal) and $1.2 \mathrm{nM}$ ]. Relative protein expression was calculated as percentage to basal. Histograms show densitometric analysis of Notch protein expression using NIH image J software. D. Leptin-induced phosphorylated VEGFR-2 (pVEGFR-2) levels in HUVEC is reduced by VEGFR-2 kinase inhibition. HUVEC were treated for 24 hours with leptin [0 (basal) and $1.2 \mathrm{nM}$ ] and inhibitors of VEGFR-2 kinase (SU5416; $5 \mu \mathrm{mol} / \mathrm{L}$ ) and leptin receptor (LPrA2; $1.2 \mathrm{nM})$. Levels of VEGFR-2 in cell lysates were determined by ELISA (R\&D Systems). Assay dynamic range and sensitivity were 78.1 $5,000 \mathrm{pg} / \mathrm{mL}$ and $11.4 \mathrm{pg} / \mathrm{ml}$, respectively. E. Leptin induction of VEGFR-2 mRNA in HUVEC is reduced by Notch knockdown. Quantitative results from real-time PCR of VEGFR-2 and Notch1 and Notch3 mRNA expression in HUVEC treated with leptin and Notch1 and Notch3 SiRNA. RNA expression was calculated by normalizing values to GAPDH mRNA. Relative mRNA expression was calculated to basal. F. Leptin induction of VEGFR-2 phosphorylation in endothelial cells. WB representative results from leptin-induced phosphorylation of VEGFR-2 in HUVEC and PAEC VEGFR-2 in absence of VEGF. Cells were incubated with leptin (0 and $1.2 \mathrm{nM})$ and VEGFR-2 kinase inhibitor (SU5416; $5 \mu \mathrm{mol} / \mathrm{L})$ for 24 hours. VEGF (25 ng/ml) was used as a positive control. Levels of phosphorylated VEGFR-2 (pVEGFR-2 at Y951, Y966, Y1059 and Y1175) were determined by WB using specific antibodies. Histograms show densitometric analysis of pVEGFR-2 proteins using NIH image $\mathrm{J}$ software. GAPDH was used as a loading control. Relative protein expression was calculated as percentage to basal. Data is presented as an average \pm s.d. from three independent experiments. Su: SU5416; SiControl: siRNA control. a: $\mathrm{p}<0.05$ when compared to basal. b: $\mathrm{p}<0.05$ when compared to endothelial cells treated with leptin.

\section{Figure 8. A functional OB-R/VEGFR/Notch axis stimulates leptin-induced angiogenic features in} endothelial cells

Leptin-induces Notch expression in endothelial cells through activation of VEGFR-1 and VEGFR-2 in the absence of VEGF. Leptin induces VEGFR-2 expression and transphosphorylation at Y951, Y966, and Y1175, that in turn induces the expression of Notch genes/proteins. These effects of leptin increase 
endothelial cell proliferation, S-phase progression, and tube formation. Inhibition of OB-R, VEGFR-2 or Notch signaling negatively impacts leptin pro-angiogenic effects in endothelial cells. 


\section{References}

Aird, W. C., 2007. Phenotypic heterogeneity of the endothelium: II. Representative vascular beds. Circ.Res., 100, 174-190.

Battle, M., Gillespie, C., Quarshie, A., Lanier, V., Harmon, T., Wilson, K. et al., 2014. Obesity induced a leptin-Notch signaling axis in breast cancer. Int.J.Cancer, 134, 1605-1616.

Bouloumie, A., Drexler, H. C., Lafontan, M., Busse, R., 1998. Leptin, the product of Ob gene, promotes angiogenesis. Circ.Res., 83, 1059-1066.

Calle, E. E., Kaaks, R., 2004. Overweight, obesity and cancer: epidemiological evidence and proposed mechanisms. Nat.Rev.Cancer, 4, 579-591.

Ferrara, N., Gerber, H. P., LeCouter, J., 2003. The biology of VEGF and its receptors. Nat.Med., 9, 669676.

Fischer, C., Schneider, M., Carmeliet, P., 2006. Principles and therapeutic implications of angiogenesis, vasculogenesis and arteriogenesis. Handb.Exp.Pharmacol., 157-212.

Garonna, E., Botham, K. M., Birdsey, G. M., Randi, A. M., Gonzalez-Perez, R. R., Wheeler-Jones, C. P., 2011. Vascular endothelial growth factor receptor-2 couples cyclo-oxygenase-2 with pro-angiogenic actions of leptin on human endothelial cells. PLoS One, 6, e18823.

Gerhardt, H., Golding, M., Fruttiger, M., Ruhrberg, C., Lundkvist, A., Abramsson, A. et al., 2003. VEGF guides angiogenic sprouting utilizing endothelial tip cell filopodia. J.Cell Biol., 161, 1163-1177.

Gillespie, C., Quarshie, A., Penichet, M., Gonzalez-Perez, R.R., 2012. Potential Leptin of Leptin Signaling in DMBA-induced Mammary Tumors by Non-Responsive C57/BL6J Mice Fed a High-Fat Diet. J.Carcinogene Mutagene, 3,132 
Gonzalez, R. R., Leavis, P. C., 2003. A peptide derived from the human leptin molecule is a potent inhibitor of the leptin receptor function in rabbit endometrial cells. Endocrine, 21, 185-195.

Gonzalez-Perez, R. R., Lanier, V., Newman, G., 2013. Leptin's Pro-Angiogenic Signature in Breast Cancer. Cancers.(Basel), 5, 1140-1162.

Gonzalez-Perez, R. R., Xu, Y., Guo, S., Watters, A., Zhou, W., Leibovich, S. J., 2010. Leptin upregulates VEGF in breast cancer via canonic and non-canonical signalling pathways and NFkappaB/HIF-1alpha activation. Cell Signal., 22, 1350-1362.

Guo, S., Colbert, L. S., Fuller, M., Zhang, Y., Gonzalez-Perez, R. R., 2010. Vascular endothelial growth factor receptor-2 in breast cancer. Biochim.Biophys.Acta, 1806, 108-121.

Guo, S., Gonzalez-Perez, R. R., 2011. Notch, IL-1 and leptin crosstalk outcome (NILCO) is critical for leptin-induced proliferation, migration and VEGF/VEGFR-2 expression in breast cancer. PLoS.One., 6, e21467.

Guo, S., Liu, M., Gonzalez-Perez, R.R., 2011. Role of Notch and its oncogenic signaling crosstalk in breast cancer. Biochim. Biophys. Acta, 1815, 197-213.

Guo, S., Liu, M., Wang, G., Torroella-Kouri, M., Gonzalez-Perez, R.R., 2012. Oncogenic role and therapeutic target of leptin signaling in breast cancer and cancer stem cells. Biochim. Biophys. Acta, $1825,207-222$.

Halaas JL, Gajiwala KS, Maffei M, Cohen SL, Chait BT, Rabinowitz D, et al., 1995. Weight-reducing effects of the plasma protein encoded by the obese gene. Science, 269:543-6

Hellstrom, M., Phng, L. K., Gerhardt, H., 2007a. VEGF and Notch signaling: the yin and yang of angiogenic sprouting. Cell Adh.Migr., 1, 133-136. 
Hellstrom, M., Phng, L. K., Hofmann, J. J., Wallgard, E., Coultas, L., Lindblom, P. et al., 2007b. D114 signalling through Notch1 regulates formation of tip cells during angiogenesis. Nature, 445, 776-780.

Hoeben, A., Landuyt, B., Highley, M. S., Wildiers, H., Van Oosterom, A. T., \& De Bruijn, E. A., 2004. Vascular endothelial growth factor and angiogenesis. Pharmacol.Rev., 56, 549-580.

Holmqvist, K., Cross, M. J., Rolny, C., Hagerkvist, R., Rahimi, N., Matsumoto, T. et al., 2004. The adaptor protein shb binds to tyrosine 1175 in vascular endothelial growth factor (VEGF) receptor-2 and regulates VEGF-dependent cellular migration. J.Biol.Chem., 279, 22267-22275.

Kroll, J., Waltenberger, J., 1997. The vascular endothelial growth factor receptor KDR activates multiple signal transduction pathways in porcine aortic endothelial cells. J.Biol.Chem., 272, 32521-32527.

Kumano, K., Chiba, S., Kunisato, A., Sata, M., Saito, T., Nakagami-Yamaguchi, E. et al., 2003. Notch1 but not Notch2 is essential for generating hematopoietic stem cells from endothelial cells. Immunity., 18, 699-711.

Lee, Y. J., Karl, D. L., Maduekwe, U. N., Rothrock, C., Ryeom, S., D'Amore, P. A. et al., 2010. Differential effects of VEGFR-1 and VEGFR-2 inhibition on tumor metastases based on host organ environment. Cancer Res., 70, 8357-8367.

Lipsey, C.C., Harbuzariu, A., Daley-Brown, D., Gonzalez-Perez, R.R., 2016. Oncogenic role of leptin and NILCO in cancer. World J. Methodol., 6, 43-55

Liu, Z. J., Shirakawa, T., Li, Y., Soma, A., Oka, M., Dotto, G. P. et al., 2003. Regulation of Notch1 and D114 by vascular endothelial growth factor in arterial endothelial cells: implications for modulating arteriogenesis and angiogenesis. Mol.Cell Biol., 23, 14-25. 
Matsumoto, T., Bohman, S., Dixelius, J., Berge, T., Dimberg, A., Magnusson, P. et al., 2005. VEGF receptor-2 Y951 signaling and a role for the adapter molecule TSAd in tumor angiogenesis. EMBO J., 24, 2342-2353.

Noguera-Troise, I., Daly, C., Papadopoulos, N. J., Coetzee, S., Boland, P., Gale, N. W. et al., 2006. Blockade of Dl14 inhibits tumour growth by promoting non-productive angiogenesis. Nature, 444, 10321037.

Rene, G. R., Watters, A., Xu, Y., Singh, U. P., Mann, D. R., Rueda, B. R. et al., 2009. Leptin-signaling inhibition results in efficient anti-tumor activity in estrogen receptor positive or negative breast cancer. Breast Cancer Res., 11, R36.

Schroeter MR, Schneiderman J, Schumann B, Gluckermann R, Grimmas P, Buchwald AB, et al. 2007 Expression of the leptin receptor in different types of vascular lesions. Histochem Cell Biol., 128:323-33.

Shawber, C. J., Das, I., Francisco, E., \& Kitajewski, J., 2003. Notch signaling in primary endothelial cells. Ann.N.Y.Acad.Sci., 995, 162-170.

Sierra-Honigmann, M. R., Nath, A. K., Murakami, C., Garcia-Cardena, G., Papapetropoulos, A., Sessa, W. C. et al., 1998. Biological action of leptin as an angiogenic factor. Science, 281, 1683-1686.

Suchting, S., Freitas, C., le, N. F., Benedito, R., Breant, C., Duarte, A. et al., 2007. The Notch ligand Delta-like 4 negatively regulates endothelial tip cell formation and vessel branching. Proc.Natl.Acad.Sci.U.S.A, 104, 3225-3230.

Takeshita, K., Satoh, M., Ii, M., Silver, M., Limbourg, F. P., Mukai, Y. et al., 2007. Critical role of endothelial Notch1 signaling in postnatal angiogenesis. Circ.Res., 100, 70-78. 
Tammela, T., Zarkada, G., Wallgard, E., Murtomaki, A., Suchting, S., Wirzenius, M. et al., 2008. Blocking VEGFR-3 suppresses angiogenic sprouting and vascular network formation. Nature, 454, 656660.

Waltenberger, J., Claesson-Welsh, L., Siegbahn, A., Shibuya, M., Heldin, C.H., 1994. Different signal transduction properties of KDR and Flt1, two receptors for vascular endothelial growth factor. J. Biol. Chem. 269, 26988-26995.

Waltenberger, J., Mayr, U., Pentz, S., Hombach, V., 1996. Functional upregulation of the vascular endothelial growth factor receptor KDR by hypoxia. Circulation 1996, 94,1647-1654.

Williams, C. K., Li, J. L., Murga, M., Harris, A. L., Tosato, G., 2006. Up-regulation of the Notch ligand Delta-like 4 inhibits VEGF-induced endothelial cell function. Blood, 107, 931-939.

Vogel, C., Marcotte, E.M., 2012. Insights into the regulation of protein abundance from proteomic and transcriptomic analyses. Nat. Rev. Gen. 13, 227-232. 

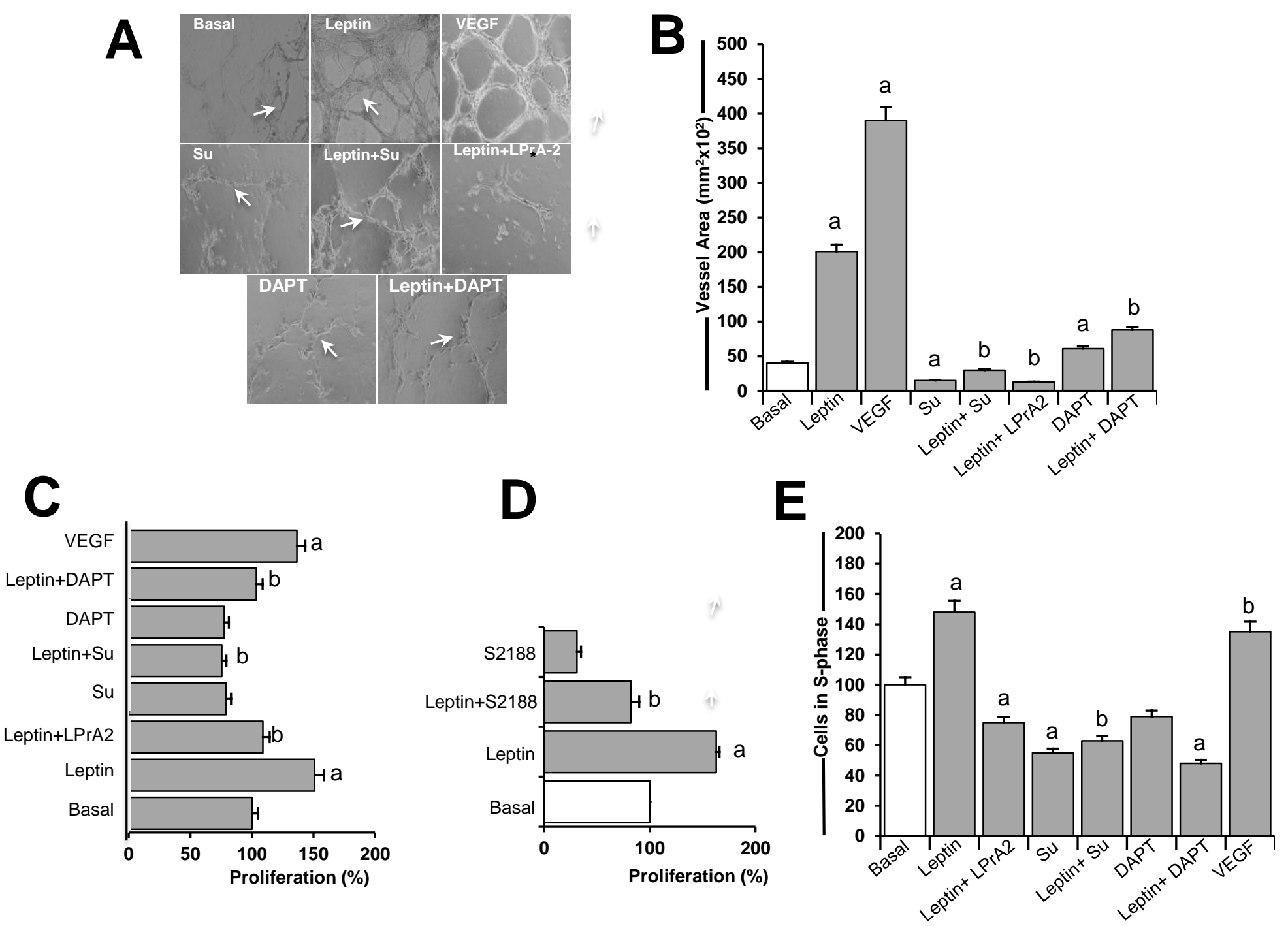

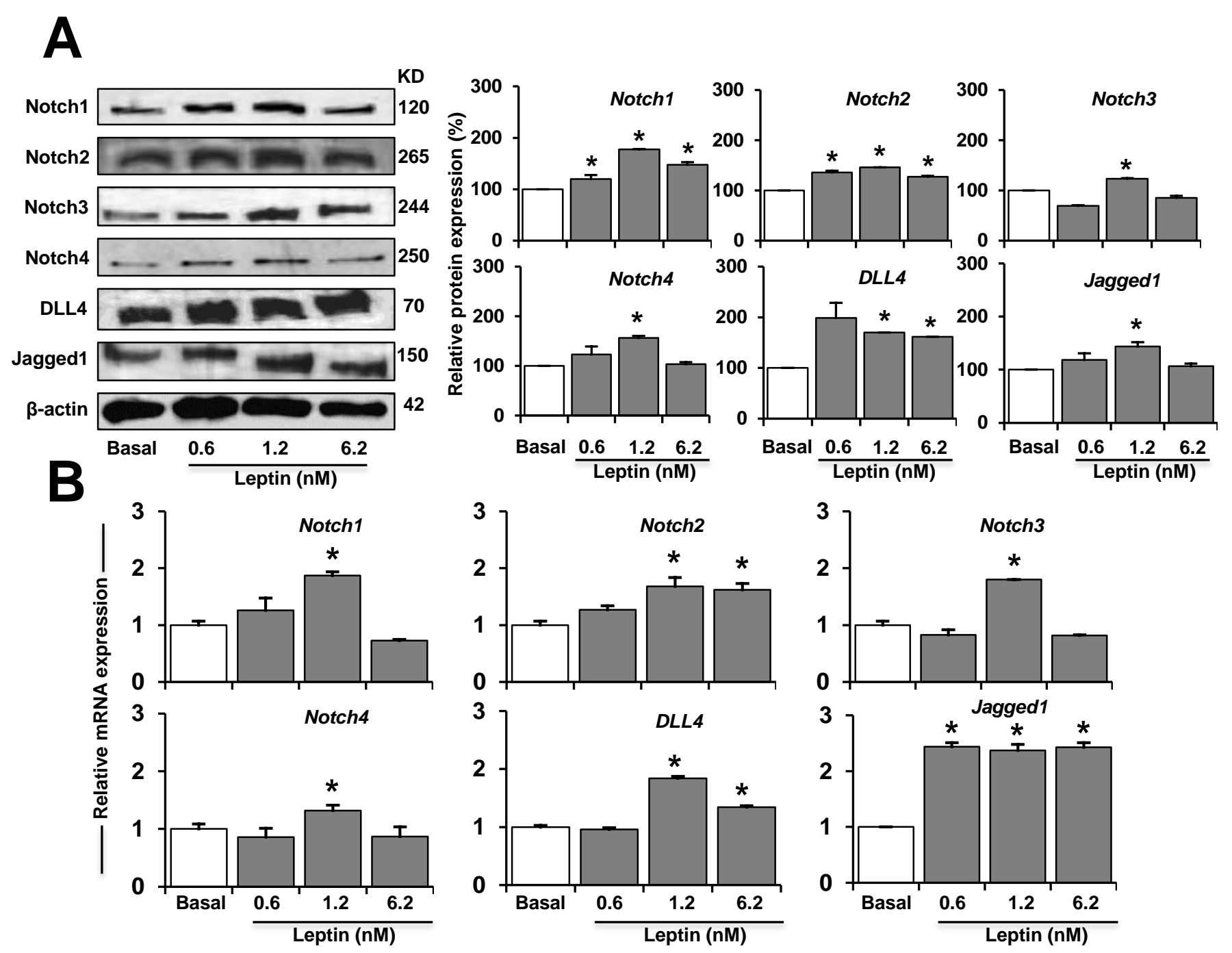

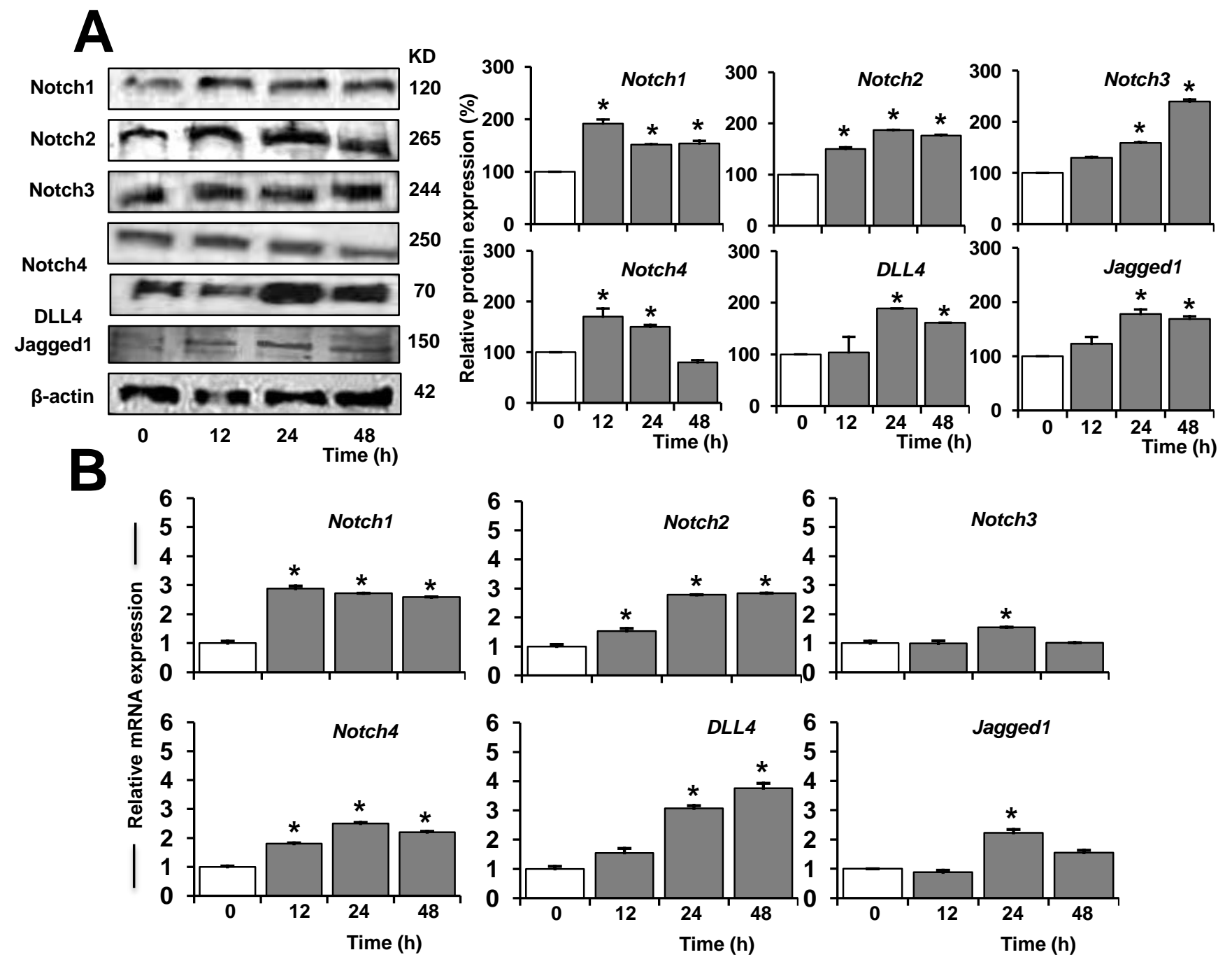


\section{A}

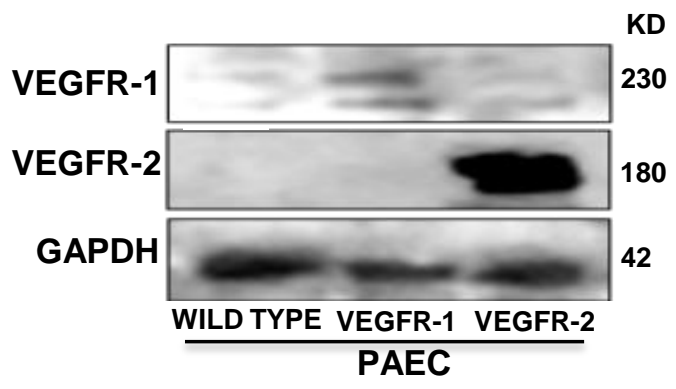

B

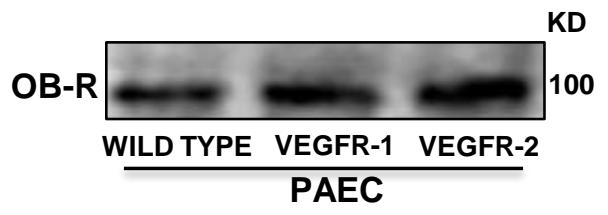

PAEC
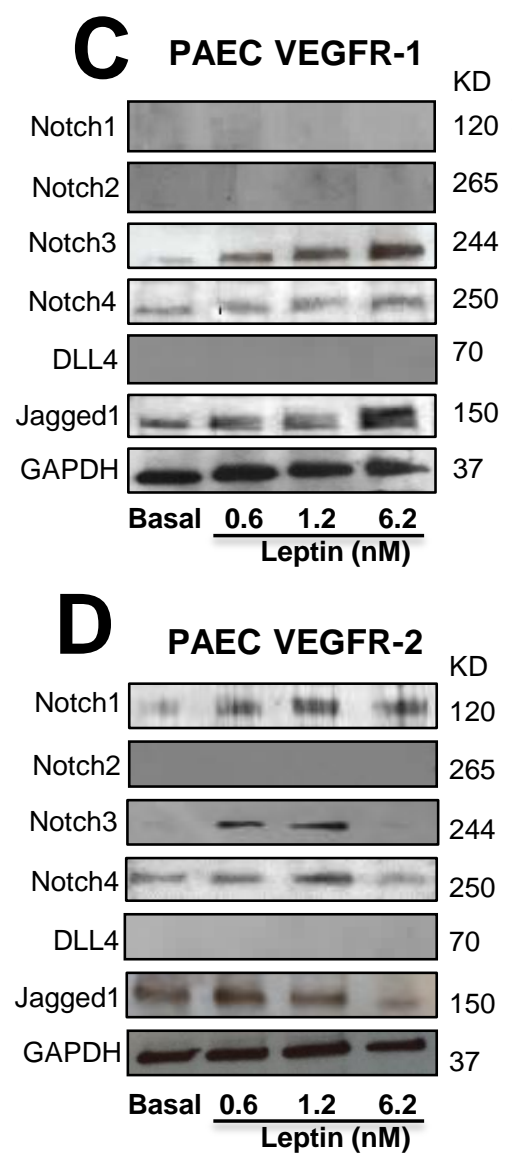

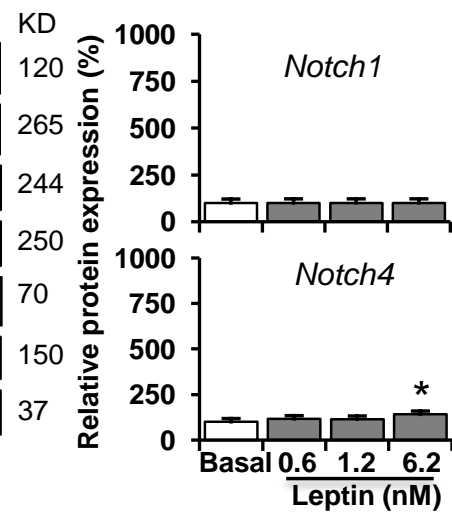

PAEC VEGFR-1

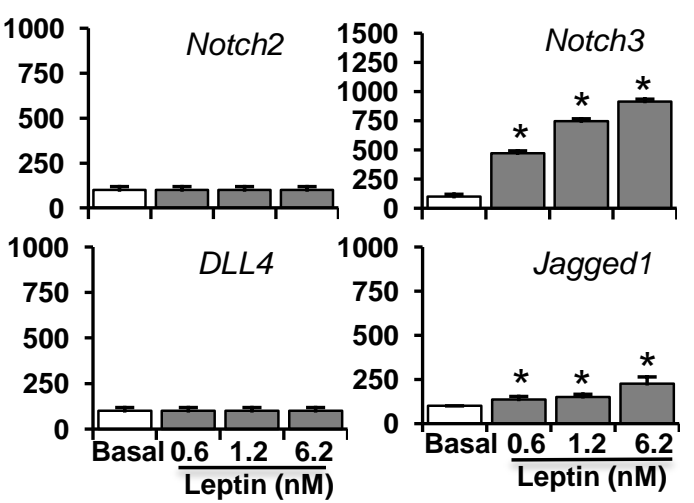

PAEC VEGFR-2

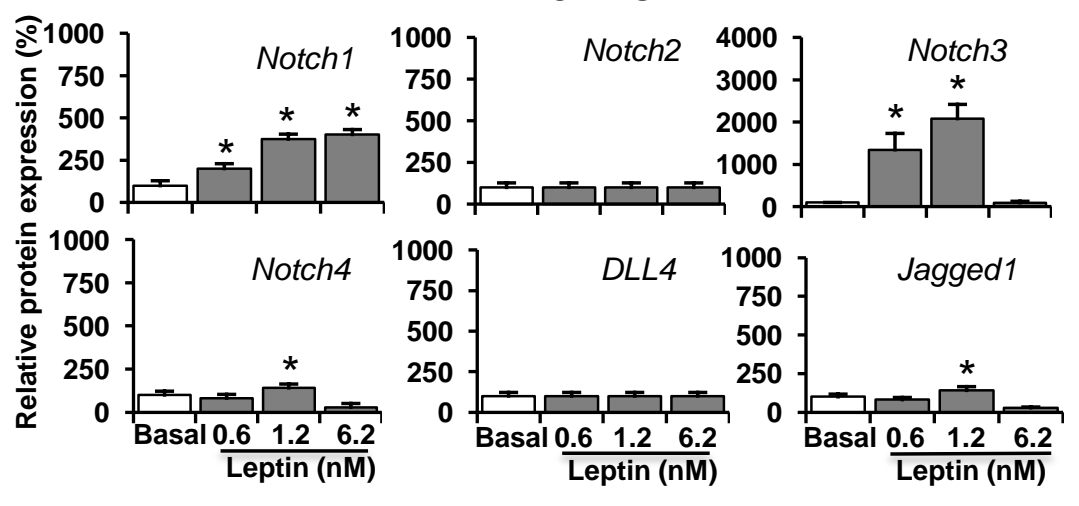




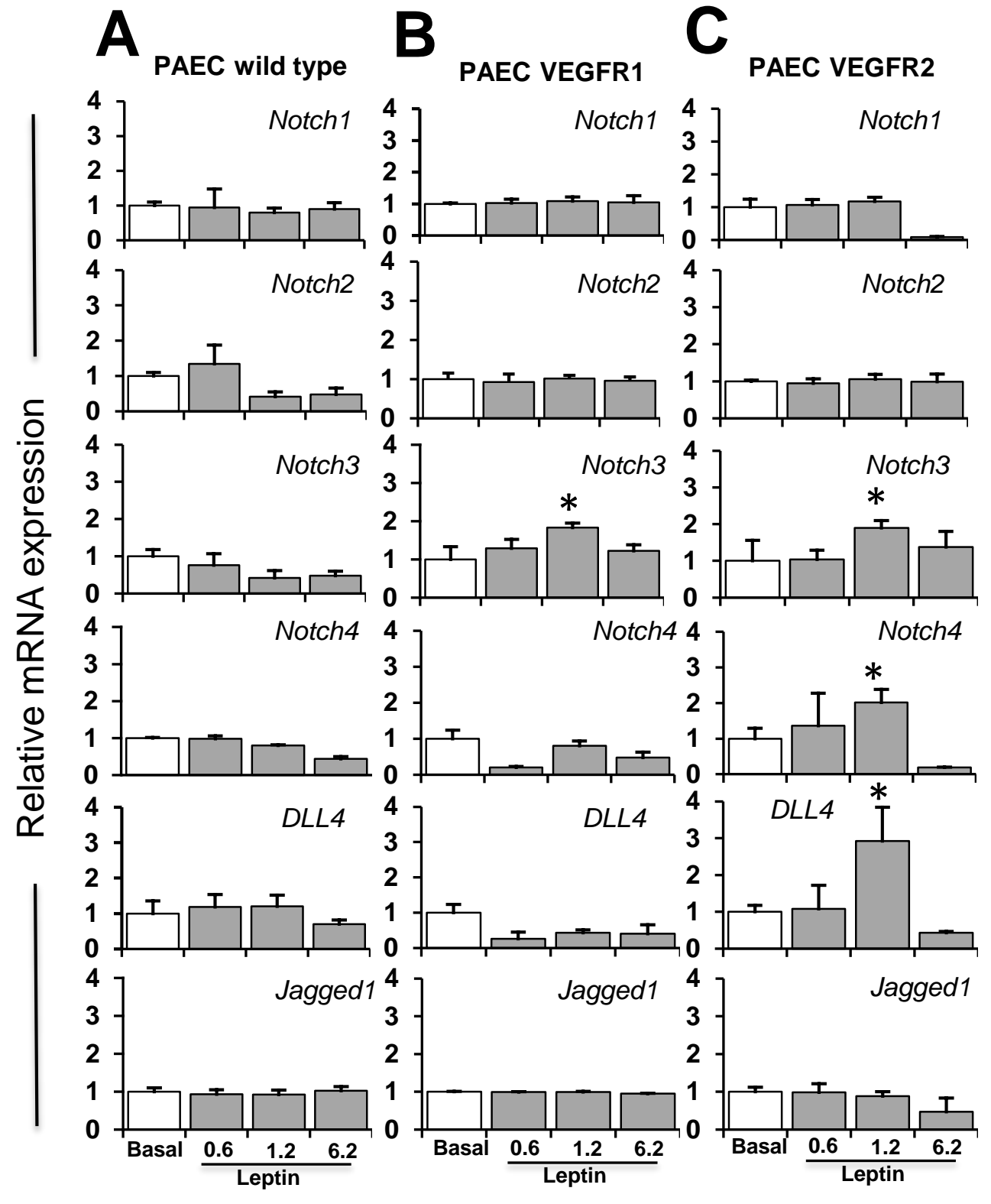




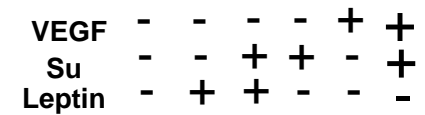

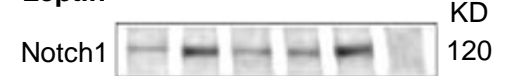

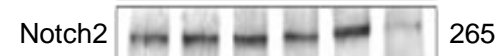

Notch3 $\mathbf{n}-\mathbf{a}=250$

Notch4

$\beta$-actin

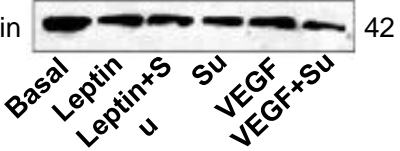

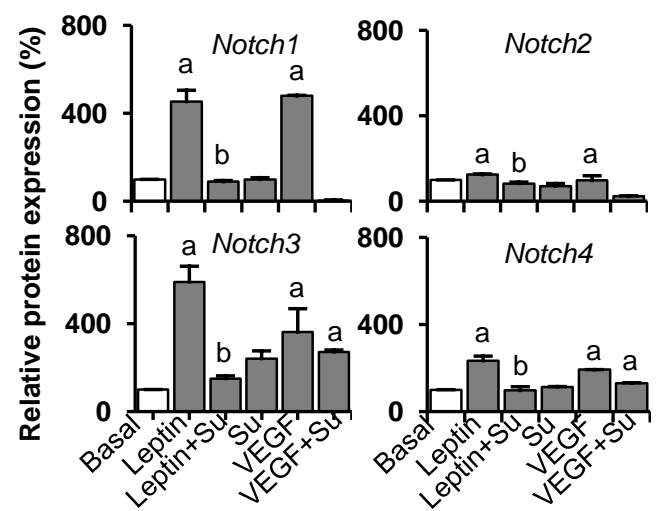

Silencing VEGFR-2
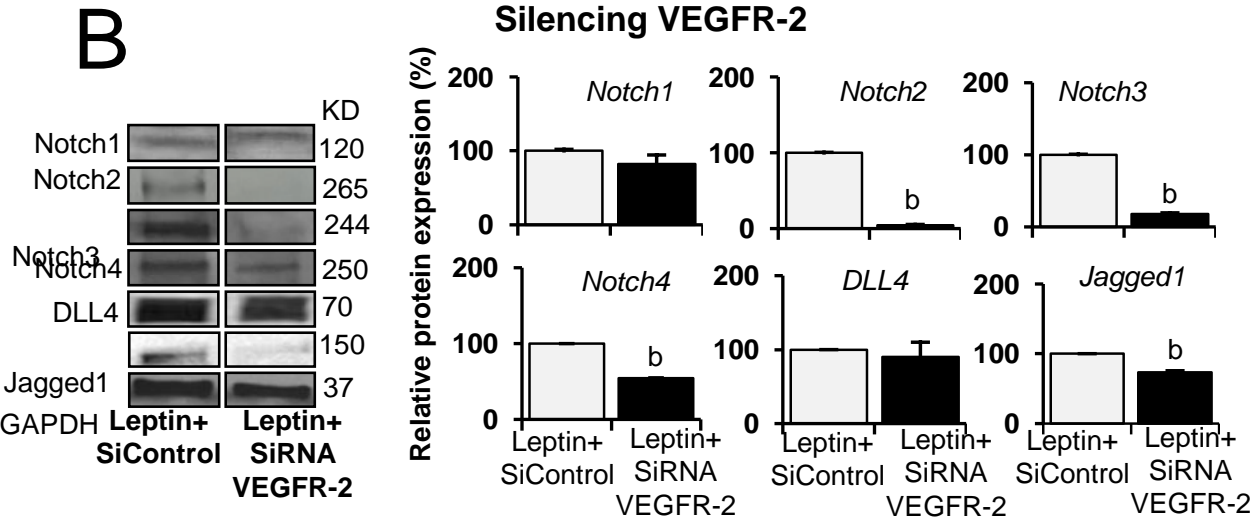

0

Silencing VEGFR-1 and VEGFR-2

Protein

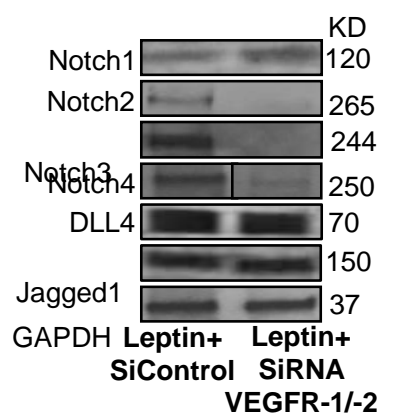

VEGFR-1/-2

D

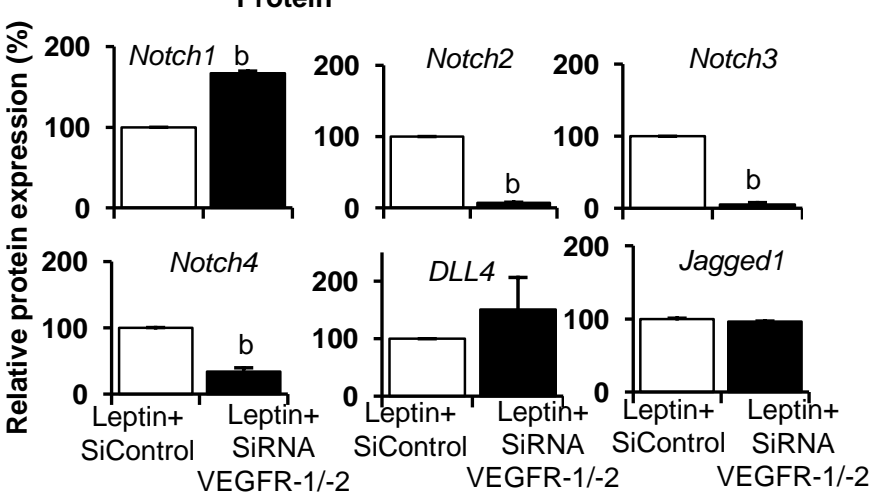

mRNA
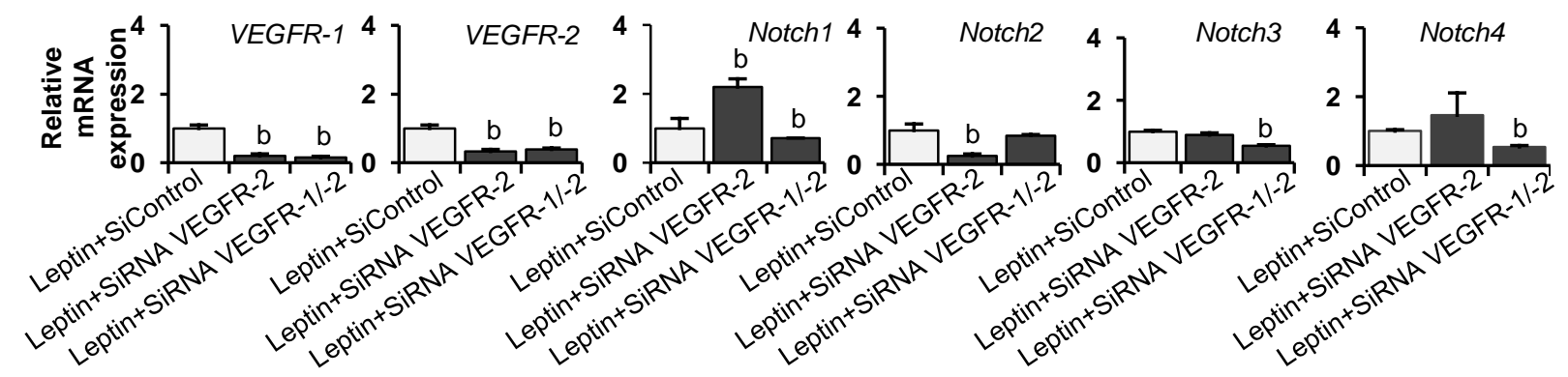

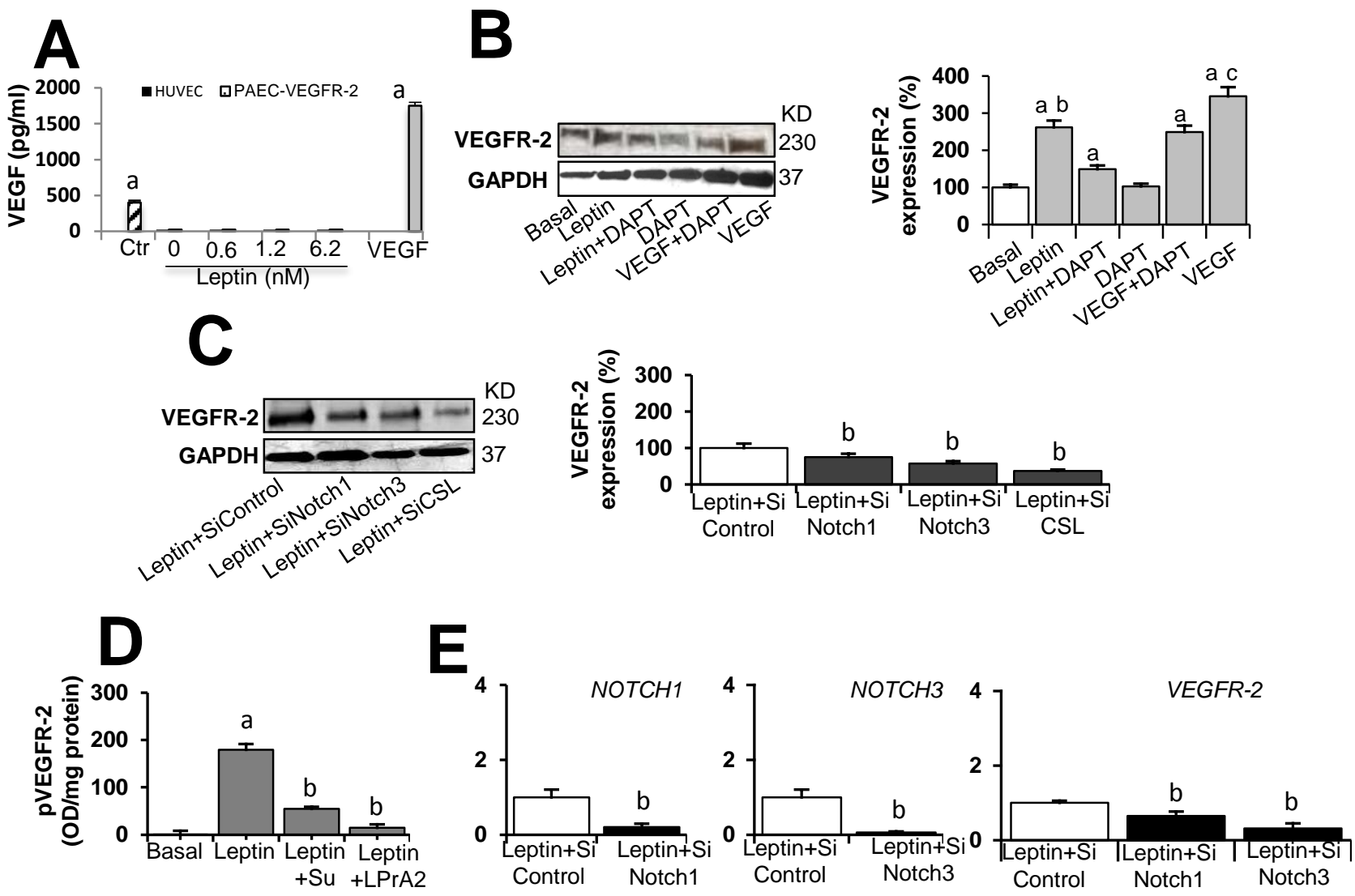

\section{HUVEC}

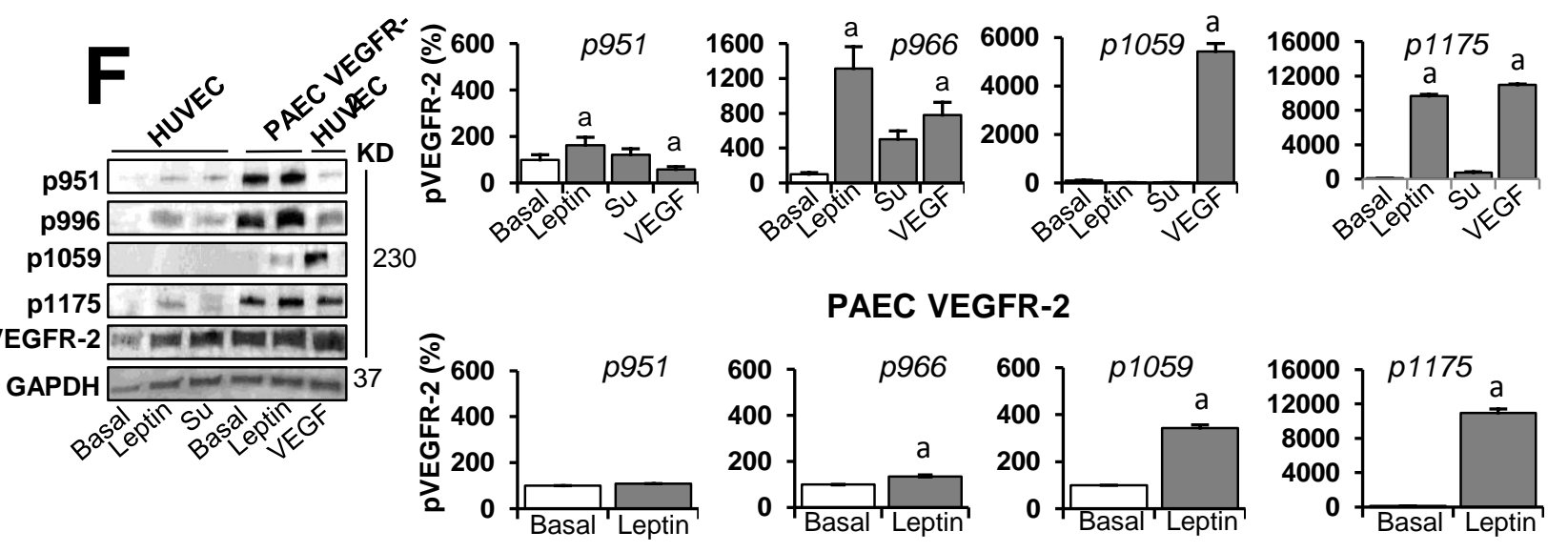




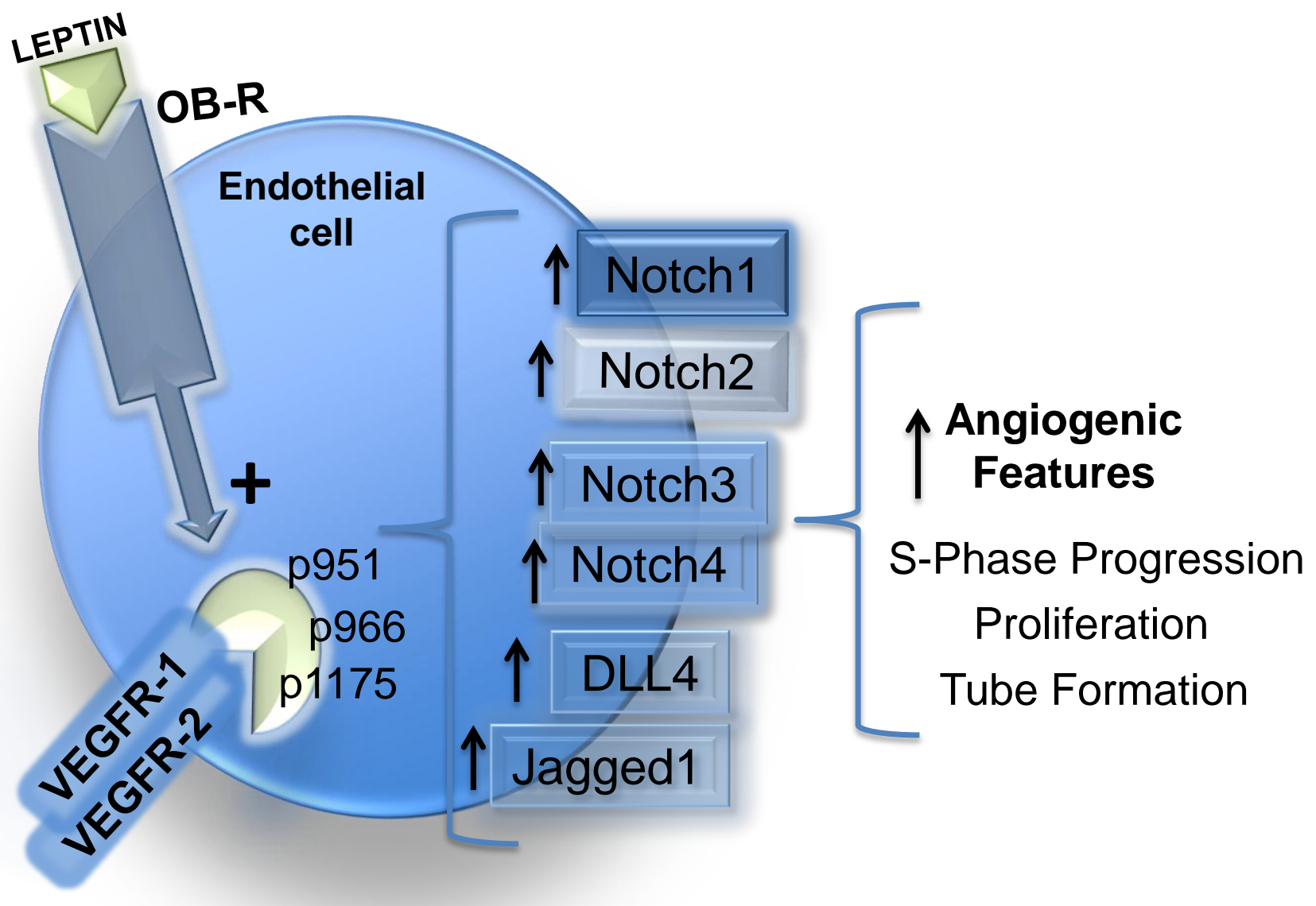

